\title{
Erratum to: The Influence of the Earth's Oblateness on the Energy Integral and Some Characteristics of a Spacecraft's Orbit
}

\author{
V. V. Ivashkin ${ }^{a, b}$, * \\ ${ }^{a}$ Keldysh Institute of Applied Mathematics, Russian Academy of Sciences, Moscow, Russia \\ ${ }^{b}$ Bauman Moscow State Technical University, Moscow, 105005 Russia \\ *e-mail:Ivashkin@keldysh.ru
}

Received November 1, 2021; revised November 1, 2021; accepted November 1, 2021

DOI: $10.1134 /$ S0010952521120029

The article "The Influence of the Earth's Oblateness on the Energy Integral and Some Characteristics of a Spacecraft's Orbit", written by V. V. Ivashkin, was originally published electronically in Springer-Link on October 14, 2021 without Open Access. After publication in volume 59, issue 5, pages 324-327 the authors decided to make the article an Open Access publication. Therefore, the copyright of the article has been changed to (C) The Author(s) 2021 and the article is forthwith distributed under the terms of a Creative
Commons Attribution 4.0 International License (http://creativecommons.org/licenses/by/4.0/, CC BY), which permits use, duplication, adaptation, distribution and reproduction of a work in any medium or format, as long as you cite the original author(s) and publication source, provide a link to the Creative Commons license, and indicate if changes were made.

The original article can be found online at https://doi.org/10.1134/S001095252105004X 